\title{
Research on Human Resource Management Innovation and Development
}

\author{
Lu Xiu \\ Economic Management Institute \\ North China Electric Power University \\ Hebei province, China \\ E-mail:1556713825@qq.com
}

\begin{abstract}
With the rapid development of economy, human resource management (HRM) has been paid more and more attention by many enterprises, and some schools also put HRM as an independent subject. People's understanding of the "human resource" is no longer stuck in the traditional "labor cost" level. Through in-depth understanding of the human resource, this paper expounds the application of Lean Six Sigma Theory in the human resource strategic management at Baosteel, and assesses and selects middle managers with entropy weight method as well as fuzzy comprehensive evaluation method so as to improve the comprehensive competitiveness of the enterprise.
\end{abstract}

Keywords-human resource; Lean Six Sigma Theory; Entropy weight method; Fuzzy comprehensive evaluation method; Entropy method

\section{INTRODUCTION}

In 2014, the First High-Level Forum on China's Frontier Issues in Human Resource Management indicated that continuous development of human resources in China had brought forward the agenda. This forum proposed that China also has a basic national condition of large population "development". Under this background, our country must give full play to the dynamic advantage of human resources in enterprises, which is the key requirement about realization of China's social development, economic transformation and cultural prosperity. To really play the dynamic advantage of human resources, the keys are to change the "low cost" into a "high quality", and to change the attitude of "I work for the world" into "the whole world to work for me".

\section{THE DEMAND OF HUMAN RESOURCES UNDER THE CONDITION} OF KNOWLEDGE ECONOMY

\section{A. The definition of human resource}

For human resources can be defined from two aspects. One is the amount of management. First of all, the development of enterprises must have a certain amount of personnel reserves, especially the core technical personnel and management personnel reserves. The second is to ensure that the human and material resources to adapt dynamically [1]. Another is the quality management, which means to use scientific methods to train staff, and to promote the growth of professional knowledge and skills. And in addition to the employees' psychological behavior management, it is essential to ensure the play of the employees' subjective initiative so as to achieve the ultimate goal of the enterprise.

\section{B. Characteristics of human resource management under the condition of knowledge economy}

- In the final analysis, the competition among countries is the competition among enterprises, and the competition among enterprises is the competition among talents. In the era of knowledge-driven economy, the talent has the absolute right to choose his right. The enterprise also needs to respect him, and to respect the staff's point of view of problems. Excellent talents and outstanding enterprises are corresponding. The higher the quality, the stronger the ability of people to get more employment opportunities for higher pay. The better the development of the enterprise, the more attention it can attract.

- From a marketing point of view to treat employees, the employees should be regarded as customers. Only in this way can we guarantee their capital value and the value of human capital. In the era of knowledge economy, the management of human resource is no longer the role of "managing people", but the complex of various roles, for example, engineers, sales staffs and customer managers, etc. First of all, human resource managers need to have all kinds of management knowledge and ability. Moreover human resource management personnel need to have the ability to push their own decision making plans to every level of the enterprise. Finally, they need to have the ability to resolve personnel relationship disputes and feedbacks [2].

- Human resource value chain management. Drawing on the knowledge of the supply chain, the establishment of human resource supply chain is imminent, that is, the recruitment of talents, training, the use of assessment and other links can be added together to form a valueadded chain. As an integrated management method, it can be analyzed both vertically and horizontally. Vertically, it defines the company through the employee' training, job rotation and the potential of the staff to tap the ability to generate business needs of 
personnel, and to achieve the maximization of the utility of internal personnel. Horizontally, it refers to the talent outsourcing or the introduction of talent from the outside, and this form has a variety of channels, such as: intermediary companies, head hunting companies, school recruitment and specialized consulting firms, etc.

\section{CHARACTERISTICS OF HUMAN RESOURCE MANAGEMENT INNOVATION ACTIVITIES}

\section{A. Support and participation of senior management}

Human resource management innovation is the result of careful thinking of senior managers within the enterprise according to the overall development strategy of the enterprise. The implementation of human resource management innovation should be carried out in a top -down form. Thus, the support and participation of senior management of enterprises has become particularly important [4]. Managers need to start from the overall strategy of the customer's point of view to clarify the human resources management problems and opportunities for improvement, and through the team's deliberations to propose a system solution of the key issues.

\section{B. Teamwork}

Human resource management activities are not a single department completed independently, which is the result of cooperation between multiple departments. As the business of each department is intricate, the overall management innovation process is the improvement and redesign of these employees' job responsibilities process, so this is the result of the cooperation of the whole team.

\section{Establish a good culture of innovation}

Corporation culture is a core idea of business development, which affect the behavior of employees in the organization. In the innovative corporate culture managers need to constantly motivate staff and improve their enthusiasm and creativity, so that employees have the courage to challenge the current situation, breaking the shackles of thinking, the courage to give innovation ideas. In addition, enterprise human resource management innovation process needs to tolerate failure.

\section{PROBLEMS TO BE SOLVED IN HUMAN RESOURCE MANAGEMENT}

\section{A. To ensure the decisive status of human resource}

When achieving the final goal of the enterprise, the human resource department often plays passively, and only ensures the normal daily routine. But the success of the enterprise must rely on their core competitiveness, and the core competition is formed by the play of human capital. To insure the decisive status of human resource, first of all, we need to guarantee that the strategic planning of human resource should be consistent with the overall strategy of the enterprise [3].The development of strategic human resource is not to solve the problem of enterprise employees in a specific period, but to produce a forward-looking, scientific human resource planning, which is a dynamic development. To improve employee' satisfaction is the key factor.

We know that the Six Sigma management was originally created by Motorola's communication department, and in the manufacturing industry, it has been popular, and eventually it has developed into the service industry, the financial industry, trade and other fields, which became almost suitable for all industries. Six Sigma management emphasizes the "customer" as the center. The solid customer is the external customer of the enterprise, and each department and the employee of the enterprise is the "customer" inside the enterprise. Enterprises are improving external customers' satisfaction at the same time, and cannot ignore the internal "customer" satisfaction, either, because people's knowledge and innovation ability is always the driving force of enterprise development. Talent is the core strength for enterprises to adapt to change and competition.

Through the combination of Lean Six Sigma and the characteristics of the enterprise, the enterprise has its advantage to obtain the breakthrough performance and to keep the longterm development advantage in the fierce competition. In 2003, Baosteel Iron and Steel Company adopted the Lean Six Sigma method to solve the problem of human resource management in its company. The solving of the "shortcomings" and "volatility" is by the Six Sigma management category, however, solving the "waste" and "cost" is made by the management category of lean. In the process, Baosteel perfectly combined the advantages of both. Seen from the strategic objectives of the development direction, the implementation of the effect, the implementation of the strategy of the various departments and the four aspects of corporate culture, Lean Six Sigma system solves the problem of human resource development of Baosteel The pilot work from the beginning to the full range of the application stimulates a variety of business promotion, training and construction of new and innovative atmosphere to get all kinds of talents for Baosteel to bring good benefits.
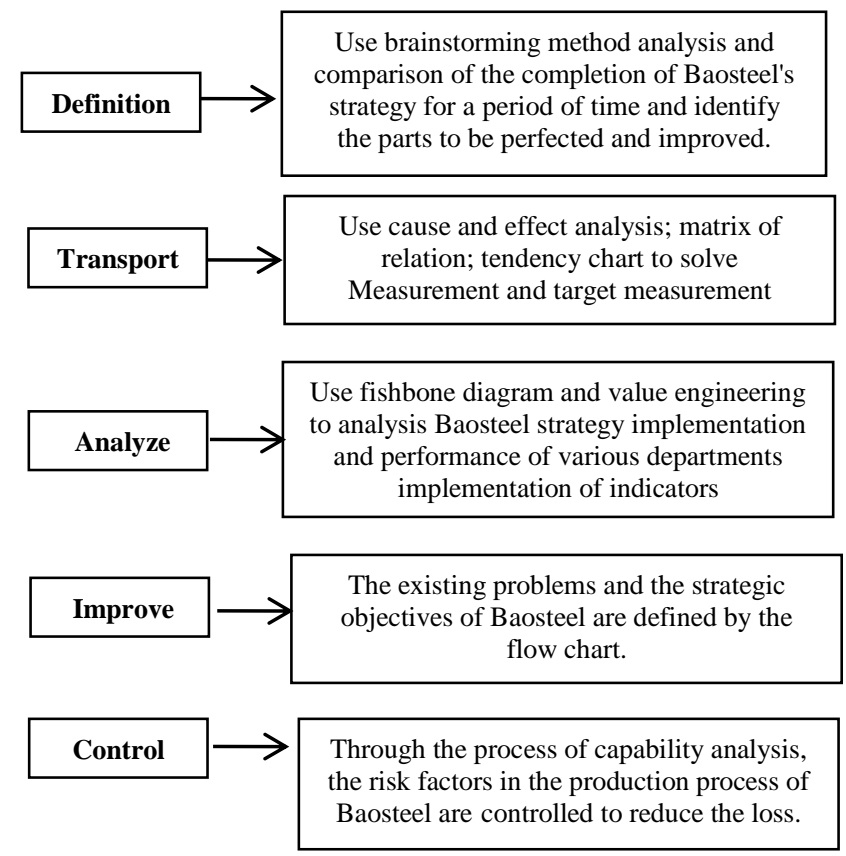

Fig. 1 Technical route of Lean Six Sigma in Baosteel 


\section{B. Establish a mechanism for selecting and keeping people}

For enterprises, reserving excellent talents can be made through four aspects: Choose, use, nurture, and stay. How to make these form a good development model is a question worth exploring. The talent is liquidity, so first of all there is a need to establish a level of talent development goals. For example, for the development of the project and the high-level high-tech talent needs a reasonable introduction, for the internal management of the enterprise also need to be aware of the training and promotion. Secondly, the use of talent is also a key part. The post-match is a principle that the enterprise should follow, which requires the management personnel to the staff ability of the scientific evaluation. Finally, to retain talent, there is a need to establish a variety of incentive mechanism. There are many reasons for the dissatisfaction of employees, such as: the importance of leadership, promotion opportunities, interpersonal relationships, material treatment, professional counterparts, and so on [5]. One or two are not enough to retain talent, it should be the incentive mechanism to form a systematic project, which needs a long time to do.

This paper uses the entropy weight method and fuzzy comprehensive evaluation to solve the problem of the selection of middle management personnel in the management of human resource.

The sales director of a company is on holiday due to unavoidable factors. During this period, the company needs to elect one temporary sales director in four outstanding sales staff in the existing position. Due to the complexity of the assessment indicators, staffs choose four factors as the final assessment of the indicators used in the existing six indicators.

$A=$ (job performance; innovative ability; executive ability; moral behavior; talent training; work attitude)

Use entropy method to determine:

$$
\mathrm{Z}=\begin{array}{llllll}
82 & 80 & 75 & 82 & 60 & 70 \\
95 & 90 & 65 & 84 & 75 & 76 \\
75 & 80 & 85 & 75 & 80 & 85 \\
86 & 70 & 65 & 68 & 80 & 76
\end{array}
$$

(1)= practicability

(2)= integrity

(3)=objectivity

(4)=planned nature

After the standardization of the matrix is: $\mathrm{R}=$

$\begin{array}{llllll}0.051 & 0.050 & 0.046 & 0.051 & 0.032 & 0.043 \\ 0.062 & 0.059 & 0.035 & 0.053 & 0.046 & 0.046 \\ 0.047 & 0.050 & 0.053 & 0.046 & 0.050 & 0.053 \\ 0.054 & 0.043 & 0.033 & 0.035 & 0.050 & 0.044\end{array}$

According to the analytic hierarchy process, the weight of each index is calculated:

$\lambda_{1}=0.193 \lambda_{2}=0.182 ; \lambda_{3}=0.15 ; \lambda_{4}=0.168 ; \lambda_{5}=0.139 ; \lambda_{6}=0.168$
Calculate the entropy:

$$
\begin{gathered}
e_{j}=-k \sum_{i=1}^{m} p_{i j} \cdot \ln p_{i j} \\
p_{i j}=r_{i j} / \sum_{i=1}^{m} r_{i j} k=1 / 1 \mathrm{n} m
\end{gathered}
$$

have to:

$e_{1}=0.992 ; e_{2}=0.994 ; e_{3}=0.986 ; e_{4}=0.845 ; e_{5}=0.988 ; e_{6}=0.995$

Entropy weight:

$$
w_{j}=\left(1-e_{j}\right) / \sum_{j=1}^{n}\left(1-e_{j}\right)
$$

$w_{1}=0.04 ; w_{2}=0.03 ; w_{3}=0.07 ; w_{4}=0.775 ; w_{5}=0.06 ; w_{6}=0.025$

For the Hamming distance: $\quad(p=1)$

$$
\begin{gathered}
\boldsymbol{L}_{1}(\lambda, \boldsymbol{j})=\sum_{j=1}^{n} \lambda_{j} \cdot\left(\mathbf{1}-\boldsymbol{r}_{i j}\right)=\mathbf{1}-\sum_{j=1}^{n} \lambda_{j} \cdot \boldsymbol{r}_{i j} \\
L_{1}(\lambda, 1)=0.152 ; L_{2}(\lambda, 2)=0.299 ; L_{3}(\lambda, 3)=0.437 ; L_{4}(\lambda, 4)=0.564 ; L_{5}(\lambda, 5)=0.684 ; L_{6}(\lambda, 6)=0.814
\end{gathered}
$$

Therefore, the first four indicators are selected as the available indicators.

Use the fuzzy comprehensive evaluation method to carry on the appraisal of the sales staff (one of the sales staff):

$\mathrm{U}=$ (job performance; executive ability; innovative ability; character and behavior)

Reviews set: V= (excellent; good; general; poor)

Using 360 degree evaluation method, select 30 representative figures to participate in the evaluation:

The fuzzy vector of the "job performance" factor is: A1= $(0.6,0.3,0.1,0.0)$

The fuzzy vector of the "executive power" factor is: A2= $(0.5,0.3,0.1,0.1)$

The fuzzy vector of the factor of "innovative ability" is: $\mathrm{A} 3=(0.4,0.2,0.3,0.1)$

The fuzzy vector of the "words and deeds" factor is: A4= $(0.3,0.2,0.3,0.2)$

The above five single factor evaluation results to synthesize a matrix, so the fuzzy relation matrix from $\mathrm{U}$ to $\mathrm{V}$ is obtained:

$$
R=\left(\begin{array}{c}
A_{1} \\
A_{2} \\
A_{3} \\
A_{4}
\end{array}\right)=\left(\begin{array}{lllc}
0.6 & 0.3 & 0.1 & 0 \\
0.5 & 0.3 & 0.1 & 0.1 \\
0.4 & 0.2 & 0.3 & 0.1 \\
0.3 & 0.2 & 0.3 & 0.2
\end{array}\right)
$$
is:

The proportion of each factor in the overall evaluation of $U$

$$
A=(0.5,0.2,0.2,0.1)
$$

Fuzzy comprehensive evaluation: 
$B=A \circ R=\left(\begin{array}{llll}0.5 & 0.2 & 0.2 & 0.1\end{array}\right)\left(\begin{array}{cccc}0.6 & 0.3 & 0.1 & 0 \\ 0.5 & 0.3 & 0.1 & 0.1 \\ 0.4 & 0.2 & 0.3 & 0.1 \\ 0.3 & 0.2 & 0.3 & 0.2\end{array}\right)$ $=(0.51,0.27,0.16,0.06)$

\section{SUMMARY}

People are the soul of the organization and the first element of management. Therefore, human resource management has become the primary task of enterprise management, business is the magic weapon and the source of profits [6]. In the face of the era of knowledge economy, and the fierce competition between countries, enterprises in China need to learn from the combination of the foreign advanced human resource management system and their own, which can occupy a favorable position in the competition of market economy.

\section{REFERENCES}

[1] Cuibo, Research on the current situation of human resource management in China, Study on the market economic theory.2008. (6):60-61(In Chinese).

[2] Bai Yanjie, Literature review and research prospects of human resources management role.Financial Economics: theory .2015(8):142-144(In Chinese).

[3] Zhu Rong.Literature review on Strategic Human Resource management: from the perspective of flexible human resources management 2012(36):546(In Chinese).

[4] Chen Jianjun,Research on Human Resource Management Model Based on Knowledge Innovation.Wuhan University of Technology. 2009:5354(In Chinese).

[5] Wang Zaixin, On the Structure of Human Resource Management Strategy in Innovative Enterprises.Regional Economic Review.2007 (4):59-59(In Chinese).

[6] Ji Hequn, Knowledge Economy and the Innovation of Human Resource Development in China. East China Normal University. 2004(In Chinese). 